\title{
Circulating Immune Complexes in Cystic Fibrosis
}

\author{
MYRON BERDISCHEWSKY, M.D." ${ }^{\prime \prime \prime}$ MATTHEW POLLACK, M.D. LOWELL S. YOUNG; M.I). \\ DAVID (HIA. Ph.D., ALAN B. OSHER, M.D., AND EUGENE V. BARNETT. M.I). \\ Divisions of Infectious Diseases and Rheumatologl. Department of Medicine, the Cistic Fibrosis Center. Department \\ of Pediatrics, UC L.A School of Medicine. Los Angeles. California. and the Deparment of Medicine. Uniformed \\ Services University of the Health Sciences. Bethesda. Marlland. US.A
}

\begin{abstract}
Summary
Recurrent respiratory infections associated with "mucoid" Pseudomonas aeruginosa characterize the advanced stages of cystic fibrosis. To determine if chronic antigenic stimulation is associated with circulating immune complexes (CIC), we assayed the sera of 20 hospitalized patients using the technique of precipitation with $4 \%$ polyethylene glycol. Elevated CIC levels, defined by $>310 \mu \mathrm{g}$ IgG per $\mathrm{ml}$, were found in 18 of 20 patients (range, 360 to 3200 $\mu \mathrm{g} / \mathrm{ml}$ ). Serum, supernatant, and resuspended precipitates were assayed for hemagglutinating antibodies against pseudomonas lipopolysaccharide (LPS or endotoxin) and exotoxin $A$ antigens. Both serum anti-LPS (range, 1:64 to 1:2048) and antitoxin titers (range, 1:64 to $1: 16,384$ ) were markedly elevated and higher than titers in supernatants and resuspended precipitates, indicating antibody excess. "Enrichment" ratios for antibodies present in CIC were calculated by proportion of titer to immunoglobulin in the precipitated complex relative to these values in serum. Mean enrichment ratios of 13.1 and $\mathbf{1 3 . 9}$ were obtained for LPS antibody before and after 2 mercaptoethanol reduction, but the mean enrichment ratio for antitoxin was only 2.07 . Serially diluted supernatants and precipitates were boiled for $1 \mathrm{hr}$ and tested for endotoxin-like activity by the limulus test. At $>1: 8$ dilutions, precipitates were positive, and supernatants were negative. These findings indicate that CIC"s are common in advanced cystic fibrosis, and analysis of the precipitated complexes demonstrates sig. nificant ( $>13$-fold) enrichment of antibodies against LPS but not exotoxin antigens, as well as endotoxin-like activity in boiled precipitates.
\end{abstract}

\section{Speculation}

Immune complex-mediated pulmonary damage may contribute to the tissue destruction observed in patients with advanced cystic fibrosis. Studies correlating circulating immune complexes levels to extent of disease, pulmonary function, response to therapy. and prognosis might provide the impetus to reduce these complexes or abort their sequelae by pharmacologic means, in addition to providing an endpoint for the initiation and duration of antimicrobial therapy.

Recurrent respiratory infection, most often associated with "mucoid variant" strains of Pseudomonas aeruginosa, has become one of the major clinical management problems in the advanced stages of cystic fibrosis (CF) (17). Despite a considerable investigative effort, no consistent immunologic defect predisposing to recurrent infection has been identified (3). It is clear, however. that unlike other subjects at risk for developing life-threatening $P$. aeruginosa infection. CF patients are neither deficient in humoral antibodies against lipopolysaccharide (LPS) antigens of $P$. aeruginosa (5) nor in antibodies directed against pseudomonas (19) exotoxin $A(9)$. On the contrary, these antibody titers are among the highest observed for any group of pseudomonas-infected patients. and they often increase with recurrent infection and clinical deterioration (6). Pseudomonas bacteremia rarely, if ever. occurs in CF patients, and areas outside the respiratory tract are spared from direct involvement with bacterial infection (15). Undernutrition, clubbing, liver disease, and impaired exocrine gland function are common clinical findings besides hypoxia and respiratory failure.

Within the last 4 years, a variety of new serologic observations have been made in CF patients. These include demonstration of circulating antinuclear antibodies in 30 to $40 \%$ of subjects 15 to 25 years of age, occasional detection of circulating rheumatoid factor (7), and the finding of immune complexes both circulating in serum and localized in tissues $(6,13)$. The reports of immune complexes in these patients are particularly interesting. The first was primarily an autopsy study by McFarlane $e t a l$. (10) who used immunofluorescence to detect tissue localization of immune complexes in 5 patients with CF. The second report was that of Schiotz et al. (13) who assessed 11 CF patients chronically infected with mucoid $P$. aeruginosa. Using a complement consumption assay for detection of circulating immune complexes (CIC"s), 6 patients were found to have significantly elevated levels. Additionally, 5 had IgM antinuclear factors, and 10 were also found on skin biopsy to have a "granular" pattern of $\operatorname{IgM}$ deposition in the dermal-epidermal junction.

The purpose of the present study was two-fold: first, to use a new technique to investigate the prevalence of CIC"s in (F patients ill enough to require hospitalization: and second, to define the composition of these complexes. The assay utilized for the detection of CIC"s is based on the ability of 4" polyethylene glycol (PEG) to precipitate $\lg$ G complexes from serum without precipitating monomeric $\lg G(1,2,4)$. Antibody levels directed against the commonly occurring LPS antigens of $P$. aeruginosa and exotoxin A, a widely accepted "virulence" factor of the organism, were determined in whole serum from 20 patients with $\mathrm{CF}$ and compared to antibody titers in the precipitated complexes. Additionally, limulus assays were performed on boiled complexes to assess the presence of endotoxin-like material. The results indicate that CIC's are commonly present in these patients and that the complexes are "enriched" in LPS antibody and contain endotoxin-like material.

\section{MATERIALS AND METHOIS}

\section{PATIENT SHLLCTION}

All patients were hospitalized at the UCLA Center for the Health Sciences for treatment of respiratory infections complicating CF. Ventilatory and antimicrobial therapy were the responsibility of attending physicians, and serum specimens for determinations of CIC levels were obtained in parallel with specimens drawn to determine blood aminoglycoside levels. Informed consent was obtained from each patient or. if the subject was less than 18 years of age, from his or her parents. 


\section{PEC; PRICIPITATION OF SERUM}

Assays for CIC's were carried out after the method of Chia $e t$ al. (1). Equal volumes of sera and $8 \%$ PEG-6000 in phosphatebuffered saline (PBS) $(0.01 \mathrm{M} ; \mathrm{pH} 7.4)$ were incubated for $\mathrm{l} \mathrm{hr}$ at $4^{\circ} \mathrm{C}$. Mixtures were centrifuged at $1000 \times \mathrm{g}$ for $1 \mathrm{hr}$ at $4^{\circ} \mathrm{C}$. The precipitates were then washed with $4 \%$ PEG and resuspended in PBS to the initial volume of sera, and the $\operatorname{IgG}$ content was measured by radial immunodiffusion. The mean value for normal subjects is $122 \pm 65 \mu \mathrm{g} / \mathrm{ml}$ (S.D.)

MEASUREMENT OF ANTI-IgC; RHEUMATOID FAC TOR

Anti-IgG antibodies were measured by the method of Yamagata et al. (16) involving precipitation of ${ }^{125} \mathrm{I}$-radiolabeled, heat-aggregated human $\operatorname{lgG}$ by rheumatoid factor in the presence of $1 \%$ PEG. Serial two-fold dilutions were performed in a microtiter plate, and the antibody titer was determined.

\section{MEASUREMENT OF ANTI-PSEUDOMONAS ANTIBODIES}

The serum, supernatant, and PEG precipitates were available as three different materials for determination of antibodies to pseudomonas antigens. Antibodies to seven $P$. aeruginosa immunotype-specific LPS antigens (Fisher-Devlin-Gnabasik) were screened for precipitins by a microtemplate method (18). After determining the major precipitin reaction, type-specific artibody titers against the corresponding antigen were quantitated in the serum, supernatant, and precipitate by passive hemagglutiration (12). For those patients without demonstrable serum precipitins, serum was screened for hemagglutinating antibody against all seven Fisher immunotypes. The hemagglutination assay was performed with sheep erythrocytes sensitized with pseudomonas LPS's at a final concentration of $50 \mu \mathrm{g} / \mathrm{ml}$. Two-fold serial dilutions using a microtitration apparatus were carried out, following which sensitized, washed sheep erythrocytes were added, and hemagglutination patterns were assessed.

Antibodies to $P$. aeruginosa exotoxin $\mathrm{A}$ were measured in sera, supernatants, and PEG precipitates by a passive hemagglutination assay (PHA) with chromium chloride sensitized ovine erythrocytes coated with purified toxin (11).

Calculation of antibody enrichment ratios was performed using the following formula:

$$
\frac{\text { Titer in precipitate } /[\lg G] \text { precipitate }}{\text { Titer in serum } /[\lg G] \text { serum }}
$$

This was applied to each type of antibody measurement as described above or antibody activity after 2-mercaptoethanol (2$\mathrm{ME}$ ) reduction using the method of Hubner and Gengozian (8).

The limulus assay for endotoxin-like activity was carried out using limulus amebocyte lysate (Associates of Cape Cod, Inc., Woods Hole, MA). Lysate. $0.1 \mathrm{ml}$ (lot 36-8-500) was incubated for $1 \mathrm{hr}$ at $37^{\circ} \mathrm{C}$ with $0.1 \mathrm{ml}$ supernatant, resuspended precipitate, or serial dilutions of both supernatants and precipitates. The latter two materials were first boiled $\left(100^{\circ} \mathrm{C}\right)$ for $1 \mathrm{hr}$ to denature protein; material was then serially diluted 10 -fold using endotoxinfree glassware, and pipets were prepared by acid washing and dry heating at $180^{\circ} \mathrm{C}$ for $3 \mathrm{hr}$

\section{RESULTS}

\section{OBSERVED FREQUENC'Y OF (IC IN C F PATIENTS}

Twenty patients, hospitalized for exacerbation of respiratory infections complicating CF, were studied. All had multiple sputum specimens from which $P$. aeruginosa, usually of the mucoid variant type, were isolated. Eighteen of 20 patients had elevated CIC levels $(>252 \mu \mathrm{g} / \mathrm{ml}$ or $2 \mathrm{~S}$.D. above the mean controls). The range of elevated levels was 360 to $3200 \mu \mathrm{g} / \mathrm{ml}$, with a mean for all values of $1025 \mu \mathrm{g} / \mathrm{ml}$. There was a positive correlation between serum IgG levels and levels of immune complexes $(r=0.53: P<$
0.05 ) (Fig. 1). If one value, the patient with the highest level of CIC (CIC level of $3200 \mu \mathrm{g} / \mathrm{ml}$ and serum IgG level of $17.240 \mu \mathrm{g}$ / $\mathrm{ml}$ ) was omitted from the calculation, the correlation was stronger $(r=0.77: P<0.01)$.

\section{ANTIBODIES TO LPS AND ENDOTOXIN A}

Fourteen of 20 patients had detectable precipitins to one or more LPS immunotype-specific antigens of the Fisher typing system. Many patients had multiple precipitins, often directed against immunotypes IV and VI. Patients without detectable precipitating antibody all had elevated PHA titers $(>1: 32)$ against one or more LPS antigens. Figure 2 summarizes PHA titers against immunotypes IV and VI in patients with elevated titers. Mean titers are shown for whole serum, supernatant after precipitation with $4 \%$ PEG, and the precipitate resuspended in PBS to the original volume of serum before precipitation. Whole-serum titers were consistently higher than those of supernatant and precipitates.

Similarly, highest antibody titers to exotoxin A were found in whole serum (Fig. 3), whereas supernatant titers were consistently

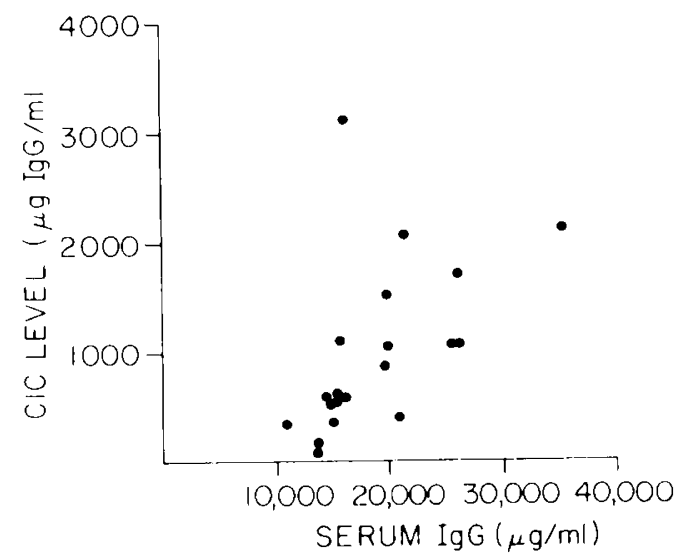

Fig. 1. Relationship between level of CIC"s (expressed in $\mu \mathrm{g} \mathrm{IgG} \mathrm{per}$ $\mathrm{ml}$ ) and serum $\operatorname{lgG}($ in $\mu \mathrm{g} / \mathrm{ml}) . r=0.52 ; P<0.05$.

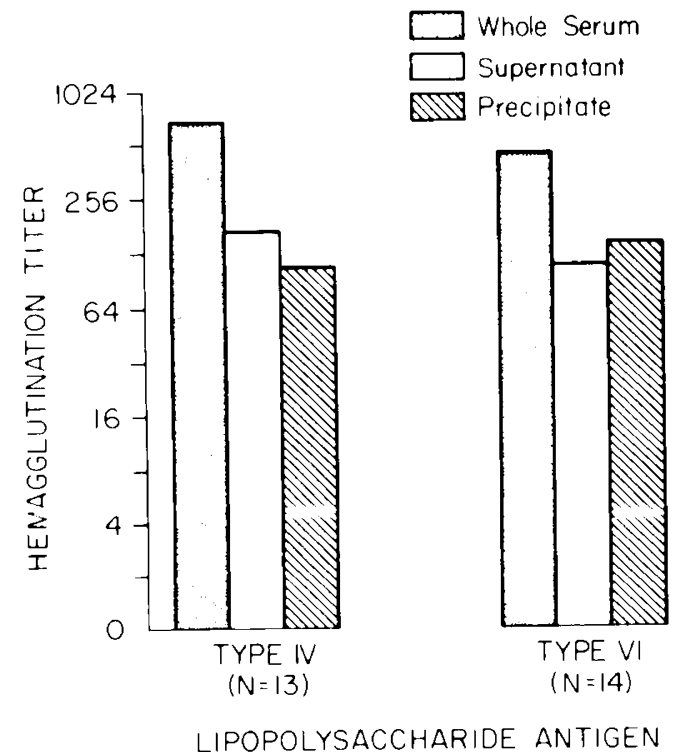

Fig. 2. Mean titers of hemagglutinating antibodies against types IV and VI $P$. aeruginosa LPS antigens of Fisher (15) in patients with elevated $(\geq 1: 32)$ titers against these antigens. Titers were measured in whole serum. and supernatant and precipitates were measured after $4 \%$ PEG precipitation. Patients lacking PHA against types IV and VI had antibody to other LPS antigens. 


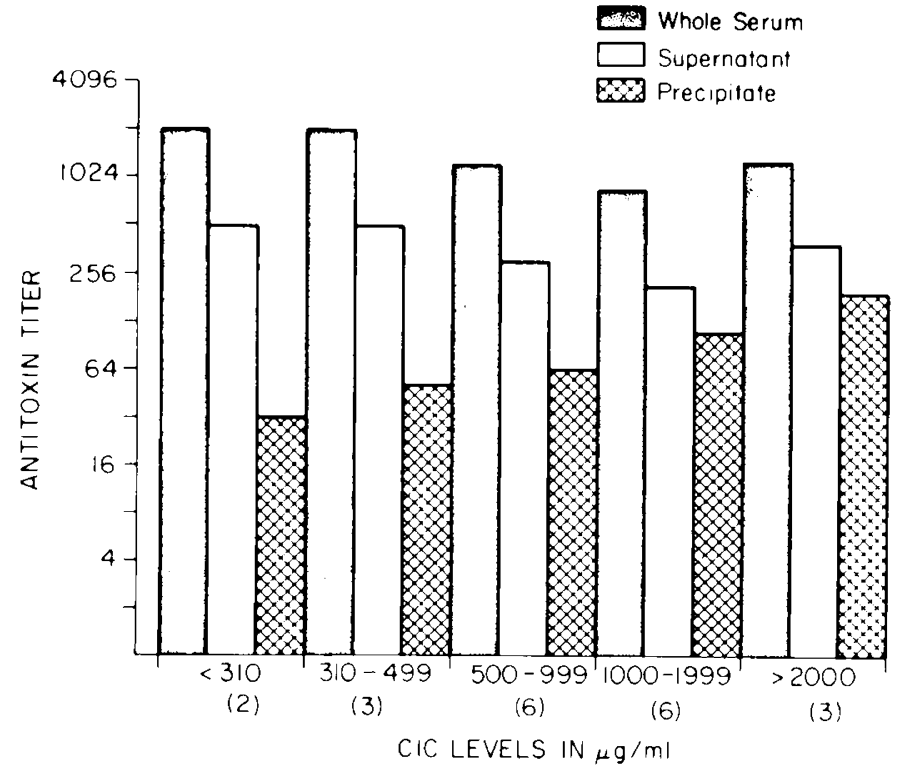

Fig. 3. Hemagglutinating antibody titers to purified Pseudomonas exotoxin $A$ in whole serum, and supernatant and precipitate after $4 \% \mathrm{PEG}$ precipitation. No correlation between CIC levels and antitoxin titers in whole serum were observed.

higher than were titers in the resuspended precipitates. All patients were found to have elevated titers to exotoxin A [titer, 1:64 or greater (12)], including the two with normal levels of CIC. There was no correlation between serum antitoxin titer and level of CIC. although the titer in the precipitates appeared to increase with CIC level.

Mean anti-IgG titers (rheumatoid factor) determined by radioimmunoassay (and expressed as $\log _{2}$ ) in 16 patients was $5.3 \pm$ 5.5 (S.D.). This did not differ significantly from 142 normal controls with a titer of $7.3 \pm 7.6$

\section{ANALYSIS OF ANTIBODY ENRICHMENT IN THE PRECIPITATES}

Although levels of antibodies to LPS and exotoxin A in whole serum are in "antibody excess." relative antibody activity factored for immunoglobulin concentration can be compared by calculation of enrichment ratios. Table 1 summarizes these calculations for anti-LPS and anti-exotoxin $A$ antibodies. Hemagglutinin titers following 2-ME reduction (putatively IgG activity) was also determined for anti-LPS antibodies. Calculated enrichment ratios for anti-LPS antibodies were virtually identical: 13.1 for total antiLPS and 13.9 for 2-ME-resistant anti-LPS antibodies. Enrichment ratios varied from 2.6 to 33.3 for whole antibodies and from 1.3 to 100 after $2-\mathrm{ME}$ reduction.

Enrichment ratios for antiexotoxin $\mathrm{A}$ antibodies ranged from 0.2 to 6.67 with a mean of 2.07 . Three patients (patients 10, 11 , and 12 ) had enrichment ratios in excess of 5.0.

\section{ENDOTOXIN-LIKE ACTIVITY IN PRECIPITATES AND SUPERNATANTS}

Supernatants and precipitates were boiled for one hr to denature any protein inhibitors of endotoxin or antibody complexed with endotoxin. However, during the earlier PEG precipitation steps, no special precautions were taken to use endotoxin-free glassware or reagents. As shown in Table 2, supernatants and precipitates were understandably positive, even from normal controls. Endotoxin-like material was undetectable by limulus test in the controls at a dilution $\geq 1: 80$. In contrast, limulus gelation occurred at these and higher dilutions in the resuspended PEG precipitates from patients with elevated CIC levels. Supernatants were negative at comparable dilutions in all patients studied. Control preparations containing an $E$. coli endotoxin formed a gel at $160 \mathrm{pg} / \mathrm{ml}$, and Pseudomonas type IV LPS produced gelation at $500 \mathrm{pg} / \mathrm{ml}$.

\section{DISCUSSION}

The detection of CIC's in the sera of patients with CF and $P$. aeruginosa pulmonary infection raises questions concerning their
Table I. Antibody enrichment ratios of anti-LPS and antitoxin antibodies ${ }^{1}$

\begin{tabular}{ccccc} 
Patient & $\begin{array}{c}\text { CIC level } \\
(\mu \mathrm{g} \operatorname{lgG} / \mathrm{ml})\end{array}$ & $\begin{array}{c}\text { Anti-LPS (hemagglutin) } \\
\text { Total }\end{array}$ & $\begin{array}{c}\text { Antixotoxin A } \\
\text { (hemagglutinin) }\end{array}$ \\
1 & 133 & 6.7 & & 1.66 \\
2 & 181 & 19.4 & & 1.25 \\
3 & 360 & 16.5 & 4.4 & 2.09 \\
4 & 360 & 5.8 & & 0.67 \\
5 & 389 & 27.5 & $100)$ & 0.86 \\
6 & 559 & 6.57 & 14.25 & 0.83 \\
7 & 618 & 13.12 & 6.0 & 0.81 \\
8 & 618 & 6.25 & 13.0 & 0.2 \\
9 & 618 & 25.8 & & 0.84 \\
10 & 679 & 5.63 & 1.37 & 6.0 \\
11 & 804 & 11.85 & 8.0 & 6.67 \\
12 & 1001 & 21.67 & 1.3 & 5.33 \\
13 & 1069 & 12.0 & 7.5 & 1.53 \\
14 & 1069 & 26.7 & 12.0 & 1.58 \\
15 & 1282 & 33.3 & 6.25 & 1.67 \\
16 & 1506 & 6.29 & 3.0 & 1.56 \\
17 & 1710 & 7.9 & 15.0 & 3.95 \\
18 & 2070 & 2.6 & 25.0 & 0.67 \\
19 & 2280 & 4.0 & 0.5 & 2.0 \\
20 & 3200 & 2.67 & 5.0 & 1.33 \\
& & & & \\
Mean enrichment & 13.1 & 13.9 & 2.07 \\
\hline
\end{tabular}

'The LPS enrichment ratio is calculated by taking the highest serum titer against all of the Fisher antigens tested and using that antigen to test serum. supernatant, and precipitate simultaneously. See "Materials and Methods" for details.

After 2-ME reduction.

Table 2. Limulus reactions on boiled precipitates and supernatants

\begin{tabular}{|c|c|c|c|c|c|c|}
\hline \multirow{2}{*}{ Patient } & \multirow{2}{*}{$\begin{array}{l}\text { CIC level } \\
(\mu \mathrm{g} \operatorname{lgG} / \mathrm{ml})\end{array}$} & \multicolumn{3}{|c|}{$1: 8 \quad 1: 80$} & \multicolumn{2}{|c|}{$1: 800$} \\
\hline & & $\mathbf{P}^{\prime}$ & $\mathrm{S}$ & $\mathbf{P}$ & $\mathrm{S}$ & $P$ \\
\hline 1 & Control & + & - & - & & \\
\hline 2 & Control & t & + & + & & \\
\hline 3 & 133 & + & \pm & \pm & - & - \\
\hline 4 & 1069 & + & - & + & & \\
\hline 5 & 1282 & + & + & + & - & + \\
\hline 6 & 1506 & + & + & + & - & + \\
\hline 7 & 2070 & + & - & + & - & + \\
\hline 8 & 3200 & + & - & + & - & + \\
\hline
\end{tabular}

'P. precipitates: S. supernatants.

composition and pathophysiologic significance. That the presence of CIC's is common in CF is now well documented by this study as well as by the previous reports of McFarlane et al. (10) and Schiotz et al. (13). In the former studies, widespread deposits of immune complexes in the respiratory and gastrointestinal tract but not in the kidneys were noted, and "membranous deposits" in the alveoli, submucosal areas of the gut wall. and the islets of Langerhans were detected. Complement was demonstrated in some complexes, and electrophoretic evidence of serum complement activation in sera was observed. Immunoglobulin eluates from immune complex-positive tissue revealed antibodies directed against staphylococcal alpha hemolysin, bovine serum albumin, and various host tissues. However, antibodies to pseudomonas antigens were not studied. McFarlane et al. (10) attempted to ascribe these findings as well as the eosinophilia and hyperglobulinemia $E$ frequently observed in $C F$ patients to a type I hypersensitivity reaction. Schiotz et al. demonstrated that the presence of CIC's was accompanied by IgM antinuclear antibodies and that skin biopsies revealed the "granular pattern" of IgM deposition. However, the significance of the latter finding is unclear because a number of CF patients apparently not infected with $P$. aeruginosa had similar IgM skin deposits.

There is a burgeoning medical and immunologic literature 
dealing with the phenomenon of CIC in various human diseases, but major problems in interpreting these results remain. More than 20 methods have been described for CIC detection, and some do not correlate well with others. Virtually all of the methods used are "indirect" and do not actually detect the primary interaction between an antigen and antibody. Some of the most popular and widely used methods are based on the putative binding of "complexes" to a lymphoblastoid cell complement receptor or quantitate complement consumption. Bacterial products like LPS can affect the latter tests. In addition, aggregated immunoglobulins will bind to Fc receptors so that the "complex" measured may not reflect the presence of an antigen-antibody interaction. Our method of $4 \%$ PEG precipitation takes advantage of the physicochemical changes as a result of antigen and antibody forming a complex. Although not as sensitive as other techniques for detecting amounts of heat-aggregated IgG, the PEG method yields similar or more frequent prevalence of CIC in various diseases (1) and has the principal advantage of yielding a precipitate which can be analyzed for antibody enrichment and antigen content (2).

It is surprising how few reports of CIC's in infectious diseases have actually established the presence of antigens complexed with antibodies as opposed to globulins bound to an antiglobulin such as "rheumatoid factor" in bacterial endocarditis. Our results cannot be attributed to a significant contribution by rheumatoid factor because only 2 of 20 patients had slightly elevated levels of anti-IgC $\mathrm{i}$ measured by a new radioimmunoassay. There is good evidence that the precipitated complexes are enriched in antibody against LPS antigens. Because a 13-to 14-fold increase is apparent irrespective of whether enrichment is calculated using titers before or after 2-ME reduction, it is appropriate to use antibody titer per $\mu \mathrm{g} \mathrm{IgG}$ for enrichment calculations. In contrast, only a two-fold antibody enrichment was demonstrable against the exotoxin $\mathrm{A}$, although 3 patients did show greater than five-fold enrichment. From these data, we can essentially exclude the "nonspecific" nature of PEG precipitation because it can concentrate one kind of antibody (anti-LPS) but not the other (anti-exotoxin A).

Pending refinement of more sensitive analytical techniques, $e$.g.. immunoassay. we cannot be certain about the antigenic composition of precipitates. During the course of our experiments, PEG and other reagents were not rendered endotoxin-free so that the results of our limulus gelation tests must be interpreted with great caution. At low dilutions, precipitates derived from serum of normal volunteers were limulus positive. By boiling supernatants and precipitates to destroy protein inhibitors of endotoxin activity (including antibody) and serially diluting these lluids, we found that precipitates from $C F$ patients with elevated CIC levels were positive, although supernatants were negative. Both supernatants and precipitates from controls were negative at identical dilutions. This identifies limulus gelation activity with CIC/PEG precipitates from CF patients, but this need not be solely attributable to the presence of pseudomonas LPS. Inasmuch as CF patients are colonized and/or infected by many other organisms, including Enterobacteriaceae (7. 15), it would not be surprising if other endotoxins were present in precipitates. Indeed, due to the vigorous immune response to many antigens, a number of antigen/ antihody interactions might be documented in PEG precipitates. In spite of the preliminary work on antigenic composition, we believe this is the first evidence of endotoxin-like activity apparently complexed with LPS antibody and circulating as an immune complex in $\mathrm{CF}$

At this point, the possible relationship between $\mathrm{CIC}$ and tissue damage in $C F$ patients remains speculative. Although a Coombs type I reaction was suggested by McFarlane's group (13), a localized type III or Arthus hypersensitivity reaction in the lung due to binding between pseudomonas antigens and large quantities of precipitating antibody has also been proposed by Schiotz et al. (13). The basis for the latter hypothesis is derived from experimental studies demonstrating immune complex lung damage resulting in hypersensitivity pneumonia, alveolitis, and emphysema. Recently, Schiotz et al. (14) have further demonstrated

(onpright (1980) International Pediatric Research Foundation. Inc.

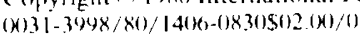

immune complexes in the sol phase of sputum from $C F$ patients. It is important to recognize that CIC's are probably not a primary abnormality in CF but probably represent an aberrant response to chronic infection. Thus, tissue destruction secondary to poorly controlled infection must still be regarded as the basic pathophysiologic event, but immune complex-mediated pulmonary damage could be a secondary phenomenon of considerable clinical significance.

Much additional work is clearly indicated with the CIC's observed in and isolated from CF patients. Besides the most pressing issue of more specific antigenic analysis, more complete studies of clinical correlates are necessary. Prospective studies relating CIC levels to disease, pulmonary function, chest roentgenograms, response to therapy, prognostic value, and a host of other variables are easy to conceive. Implication of CIC's in any of the pathologic processes observed in CF might provide the impetus to reduce these complexes or abort their sequelae by pharmacologic means or by plasmapheresis in addition to providing an endpoint for the initiation and duration of antimicrobial therapy.

\section{RIFEREN(ISS ANI) NOTISS}

1. ('hia. D., Barnett. E. V.. Yamagata, J., Knutson. D., Restivo, (... and Furst, D.: (omposition of immune complexes detected by precipitation in polyethylene glycol. (Clin. Exp. Immunol., 37: 399 (1979).

2. (reighton. W. D.. Lambert. P. H., and Meischer, P. A.: Detection of antibodies and soluble antigen-antibody complexes hy precipitation with polyethylene glycol. J. Immunul., 111: 1219 (1973).

3. 1) iaz, 1:. Mowovich. L. L... and Neter. E.: Serogroups of Psetudomonas aeruginosa and the immune response of patients with cystic tibrosis. J. Infect. Dis., 121: $269(1971)$ ).

4. Digeon, M., Laver, M., Riza. J.. and Bach. J. F.: Detection of circulating immune complexes in human sera by simplified assays with polyethylene glycol. J Immunol. Methods, 10: 165 (1977).

5. Haby. N.: Psedomonas aenuginosa cystic tibrosis. Acta Pathol. Microbiol Scand Suppl. Sect. ('Immunol. 262: I (1977).

6. Ilshy. N.: Antibodies against Psetudomonas aeruginosa in serum from normal persons and patients colonized with mucoid or non-mucoid Pseudomonas aeruginosat results obtained by crossed immunoelectrophoresis. Acta Pathol Microhiol. Scand. Sect. ('Immunol. $\$ 5$ : 142 (1977)

7. Hoiby $\mathrm{N}$ and Wiik. A.: Antibacterial precupitins and autoantibodies in serum of patients with cystic fibrosis. Scand. J. Respir. Dis., 40: $3 \times$ (1475)

x. Hubner, $K$. $F$.. and (jengozian. $N$.: Depression of the primary imnune response by 1).Penicillamine. Proc. Soc. Lxp. Biol. Med.. 1/8: 561 (1965)

9. Klinger, J. D.. Straus, D). (... Hilton. ( . B.. and Bass, J. A. Antibendies to proteases and exotoxin $A$ of Psedomonas aeruginosa in patients with cystic fibrosis demonstration by radioimmunoassay. J. Infect. Dis.. 13.8: 49 (1978).

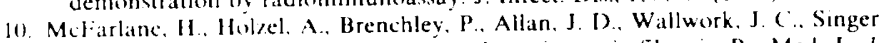
B. 1 ... and Worslev, B.: Immune complexes in cystic fibrosis. Br. Med. J., I: $423(1975)$

11. Pollack. M.. and Taylor. N. S.: Serum antibody to Pseudomonas aeruginosa exotoxin measured by a passive hemagglutination assay. J. ('lin. Microhiol., 6 . $5 \times(1977)$.

12. Pollack, M., and Young. L. S.: Protective activity of antibodies to exotoxin $A$ and lipopolysaccharide at onset of Pse'udomonas aeruginosa septicemiat in man. J. ('lin. Invest. 0.3: $276(1979)$

13. Schoty. P. O.. Hsiby, N., Juhl. F., Permin. H. Nielsen, H., and Svehag. S-E. Immune complexes in cvstic fibrosis. Acta Pathol. Microbiol. Scand. Sect. 1 Immunol.. $85: 57$ (1977).

14. Schiot, P. O.. Niclsen. H.. Hoviby, N., Clikmann. (;.. and Svehag, S. E.. Inmune complexes in the sputum of patients with cystic fibrosis suffering from chronic Preudomonas derugenesa lung infection. Acta Pathol. Microbiol. Scand. Sect. ('Immunol. sto: $37(1978)$.

15. Wood. R. F., Boat, T. F., and Doershuk, C. F, State of art: cystic tibrosis. Am. Rev Respir Dis. 113:833(1976)

16. Yamagata. J., Barnelt, 1. V., Knutson. 1). W.. Nasu, H.. and (hat. D). (hatac terization and measurement of anti-Ig(; antibedies in human sera by radioimmunoassay (RIA). J. Immunol. Methods, (in press).

17. Young. 1.. S.. and Armstrong. D: Pseudomonas aeruginosa infections. C RC C'rit. Rev. ( lin. Lab. Sci.. i: 29! (1972).

Ix Young. I S. Yu. B. H.. and Armstrong. D.: Agar-gel precipitating antiberdy in Predomomas aerraginosa infections. Infect Immun.. 2: 495 (1970).

14. In this text. "pseudomonas" refers only to the species Pseudomonas aeruginosa.

20. Requests for reprints should be addressed to: Dr. Lowell S. Young, Department of Medicine. Division of Infectious Diseases. U( I.A School of Medicine. The Center for the Health Sciences, Los Angeles. ( A $9($ )() 24 (USA)

21. This research was supported by research grant Al-1127I from the National Institute of Allergy and Infectious Diseases, a research fellowship award to Dr. Berdischewsky from the National Cystic Fibrosis Foundation, and the Julius and Alice Kantor (haritable Trust.

22. Recerved fior publication April 16. 1979.

23. Accepted for publication August 21, 1979 